\title{
HERMETO, Miriam. Canção popular brasileira e Ensino de História: palavras, sons e tantos sentidos. Belo Horizonte: Autêntica Editora, 2012. (Coleção Práticas Docentes 2)*
}

Elisgardênia de Oliveira Chaves ${ }^{1}$

Nas últimas décadas, o Ensino de História como objeto de pesquisa ganhou foros de amplitudes em todo o Brasil. As temáticas que o cercam também tem se diversificado. Em tempos assim em que, os saberes proporcionados por diferentes olhares, fontes e perspectivas dão asas a problematizações diversas sobre o ensino, mediando às relações entre a produção do conhecimento histórico o e conhecimento histórico escolar, a recente publicação "Canção popular brasileira e Ensino de História” de Miriam Hermeto, com invejável maestria, insere-se nesse debate.

O livro é rico em bibliografia e indicações de sites proporcionando acesso a arquivos diversos compostos por letras de músicas, capas de discos, jornais, entrevistas e vídeos, que cercam, dialogam e prestam informações sobre a canção popular brasileira. A primeira vista, por essa riqueza de detalhes e estratégias metodológicas crivados pelos diálogos de cores entre os textos, as diferentes cores de fundo numa mesma página, as múltiplas imagens em cores também diversas, temos a falsa impressão de estarmos manuseando um livro didático. Talvez, essa estética tenha sido criada para aguçar a imaginação do leitor a pensar sobre o objetivo maior do livro, canção popular brasileira como objeto e fonte de estudos históricos. Conteúdo, possibilidades didáticas e de pesquisa com documentos se mesclam de forma a indicar, que realmente, na educação histórica não se pode separar pesquisa de ensino.

A canção enquanto linguagem é confeccionada e consumida em larga escala por diferentes grupos socioculturais em todo o Brasil. É, portanto, amplamente acessível, presente na vida dos estudantes e atende bem aos anseios de professores pela busca de recursos pedagógicos que se aproximam do cotidiano dos alunos. Por possibilitar construir capacidades de leitura de mundo dos estudantes, enquanto sujeitos, cidadãos, trabalhadores, a canção "pode ser tomada como instrumento didático

\footnotetext{
* Resenha submetida em 14 de Outubro/2012, e aprovada em 23 de Janeiro/2013

${ }^{1}$ Doutoranda em História em História Social da Cultura pela Universidade Federal de Minas Gerais. Apoio CAPES.
} 
privilegiado no ensino de História” (HERMETO, p. 12 e 15) Isso é indiscutível. Talvez a grande questão resida nos problemas teórico-metodológicos de como tratar as canções. De antemão, ao problematizar a canção popular brasileira como objeto e fonte de estudos históricos para as práticas educacionais no Ensino Médio, a obra aqui analisada cumpre bem o objetivo a que se destina. O alvo do livro é o professor. A intenção é fazer com que ele vislumbre o interesse na realização dessas práticas, reflita sobre suas ações didáticas, e consequentemente que isso contribua para sua formação continuada.

$\mathrm{Na}$ discussão sobre a canção popular brasileira enquanto conceito historicamente construído, assunto abordado logo na introdução do livro, Miriam Hermeto, em consonância com Marcos Napolitano, justifica e escolha pelo século XX, ao afirmar ter sido nesse momento em que a historiografia concebeu o seu surgimento, a sua definição e a sua trajetória histórica. "Um produto do século XX," relacionado à sua forma fonográfica: "registro sonoro em um suporte, (disco placa, filme, suporte digital ou outro formato) que lhe dá perenidade e, em última instância, ao desenvolvimento tecnológico industrial do mundo urbanizado.” Em termos gerais, “pode ser definida como um híbrido que se constrói ao colocar diferentes tipos musicais em diálogo.” Em termos mais específicos: "narrativa que se desenvolve num espaço de tempo curto (de 2 a 4 minutos) que constrói e veicula representações sociais, a partir da combinação entre melodia e texto” (HERMETO, p. 32).

Partindo da elaboração desse conceito para justificar o recorte temporal de estudo, a autora não se detém sobre diferentes formas de expressões e usos musicais que se reportam a outras temporalidades e até mesmo espacialidades das quais, pelo menos em parte, a canção popular brasileira deriva, mescla. Fato esse certamente passível de críticas. No entanto, além do trabalho em História requerer justificativas para seus recortes, cabe aos profissionais da aérea, inspirar-se ou aprimorar-se nos passos teóricometodológicos sugeridos pela autora e construir seu próprio percurso e escolhas.

Tendo como pressuposto de que “ensinar História é ensinar teoria e metodologia,” Miriam Hermeto inspira-se teoricamente nas concepções de Marc Bloch sobre o objeto de estudo da ciência histórica: os homens e o tempo. Esse homem enquanto sujeito e objeto do conhecimento passeia sobre diferentes temporalidades: “o 
tempo da ação humana que se analisa” (passado) e “o tempo em que a análise é realizada” (presente). Esse homem - historiador - através de conceitos e métodos de pesquisa apropria-se do legado humano para a produção/ensino do conhecimento histórico. Essa produção humana configura-se em documentos.

Para discussão de documento, a autora apóias-se na definição de Jacques Le Goff, para quem “o documento é monumento,” pois sua produção está condicionada a diferentes fatores e haja vista informar sobre o modo de vida e a inserção social de quem os produziu e, ao padronizá-lo, “quis atribuir um estatuto de perenidade”. No entanto, para que a produção humana se transforme em documento para a História é necessário que se problematize e identifique "as diferentes camadas temporais”, os diferentes sujeitos e as relações existentes. Somente com esse olhar crítico se transforma os documentos "em fonte de informações sobre as relações dos homens no tempo" (HERMETO, p. 25 e 26) Assim, canção popular brasileira é entendida enquanto produção humana, documento e fonte para a história.

Para Miriam Hermeto, no uso pedagógico, esse documento/fonte, recurso didático não pode pretender apenas ilustrar historicamente os fatos narrados. Do contrário, espera-se que o professor seja capaz de trabalhar com os alunos "as especificidades de linguagem e a forma como elas se inserem na dinâmica social”, isto é, interrogar as canções a partir de seus aspectos históricos gerais, tentando perceber como ela coteja o problema, o tema que se pretende abordar e as representações que ela suscita.

A partir de Chartier e Pesavento, a autora define representação como "algo que dialoga com muitos sentidos.” Nas palavras da própria: “as representações se traduzem nos temas abordados" que podem ter "as mais diferentes abordagens melódicas ou poéticas” e isso faz com que o conceito de cação popular brasileira abarque diferentes gêneros musicais e poéticos.” Os gêneros, assim, seriam formas de definir esse produto cultural: "pelo conteúdo temático da mensagem (canção engajada, canção de amor, canção de protesto...)” ou pelo "estilo musical (bossa-nova, samba-canção, xote, rock, baião, etc.)” (HERMETO, p. 36)

De modo geral, é na busca de compreensão das representações que a canção popular brasileira proporciona que se delineiam grande parte dos estudos que a tem 
como objeto ou como fonte de estudos históricos. Nesse sentido, a partir de letras transcritas e indicações de sites de onde encontrá-las em viva voz, a autora propõe um exercício de percepção musical com vistas a auxiliar o professor a depurar seu entendimento no processo de construção de representações sociais da canção popular brasileira, bem como, compreender a adequação entre letra e melodia.

A canção popular brasileira no livro é abordada como "fato social.” A autora parte dos diferentes sujeitos envolvidos na produção, “a um só tempo cultural e comercial.” As analises recaem sobre as pessoas e instituições, os problemas históricos e sobre uma infinidade de documentos históricos que vinculam a canção e as impressões pelo público: “álbuns (LPs, CDs e DVDs), fonogramas, vestígios de interações nas redes sociais, fotografias, vídeos de performances, depoimentos, biografias, textos de críticos musicais, propagandas de álbuns e shows, reportagens sobre eventos, documentários”, etc. (HERMETO, p. 43) Por esse prisma, Hermeto dialoga com os princípios teórico-metodológico de Robert Darton. Em suas análises sobre o livro o autor insere-o na perspectiva do circuito das comunicações, envolvendo produção e consumo: do autor ao leitor, do editor ao livreiro, fornecedores e críticos.

Em grande parte esse “circuito de comunicações” imbrica as páginas da segunda parte do livro, embasando as análises e conclusões sobre a canção popular brasileira. A ênfase recai sobre os cancionistas (melodia e letra), os performers (arranjadores, instrumentalistas e cantores). Analisa um pouco da história da indústria fonográfica brasileira (primeiras gravadoras, regulamentação e crescimento da produção); capas de álbuns como fontes e acessibilidade; produtores musicais e jornalistas, como mediadores culturais e de mercado; os meios de comunicação de massa (rádio, TV) de circulação; e a apropriação da canção pelo público.

Como protagonista no assunto, isto é, na condição de professora e pesquisadora na área, Miriam Hermeto compreende que os problemas envolvendo o processo de ensino-aprendizagem em História a partir da música não são novos nem estão resolvidos. Para o professor que não tem formação na aérea, as questões mais comuns são: qual gênero ou tipo de música deve ser analisado em sala de aula? Como enfrentar a questão da linguagem musical? Como lidar com as diferenças entre as escolhas dos 
professores e o gosto musical dos alunos? Onde obter fonogramas antigos e fora do mercado, para não se prender ao que se ouve na mídia?

Mesmo que não se propunha a dar receitas prontas, com uma abordagem metodológica que dialoga questões teóricas, historiográficas e didáticas, ao longo dos textos-bases a autora intercala boxes com essa variedade de documentação acima descrita. Por essa lógica, objetiva possibilitar ao professor alternativas de trabalhos pedagógicos e sugere atividades que o permite "mediar, por meio de orientação de pesquisa, a construção de algumas capacidades de aprendizagem histórica específicas”, tais como: "lidar com documentos datados, buscando diferentes versões de canções" (HERMETO, p. 17).

Para Miriam Hermeto compreender a canção popular brasileira apenas como fato social a partir da perspectiva de circuito de comunicação não é suficiente para se entender as razões da hegemonia e de sua originalidade. Assim, a autora dedica a segunda parte do livro a "trajetória história do fenômeno e a forma como ela vem sendo interpretada.”

Mesmo que não pretenda fazer uma história da canção popular brasileira, apresenta um balanço dos estudos acadêmicos sobre o assunto. O destaque recai sobre o historiador Marcos Napolitano (autor das orelhas do livro), além de outros especialistas como a cientista social Santuza Cambraia Naves e o lingüista, músico e cancionista Luiz Tatit. A partir dessas referências, elencando para cada momento as produções, os vários sujeitos envolvidos a exemplo de cancionistas, compositores e cantores, bem como os vários gêneros, constrói uma narrativa sobre as mudanças e continuidades na canção popular brasileira, no início do século XX aos dias atuais. Inicia com a legitimação do samba, seguindo do samba-canção à bossa-nova, MPB e jovem Guarda, tropicalismo, canção romântica e pilantragem. Na ênfase sobre a diversidade cancional dos anos 1970, analisa o rock nacional, rap e funk. Por fim para as décadas de 1980 e 1990 mostra a diversificação do mercado cancional brasileiro com três gêneros em especifico: sertanejo, axé e pagode e conclui com argumentos sobre a questão: “o século XXI: para onde vai a canção popular brasileira?”

As propostas didáticas para esse ponto dão-se no sentido de ampliar as possibilidades do "leitor/professor - não especialista em música, mas em história” a 
desenvolver a percepção musical: desde a audiência, os diversos gêneros a elementos que compõem a "gramática musical,” a relação texto e melodia, arranjo, interpretação e ênfase temática.

Na última parte do texto, Miriam Hermeto propõe uma proposta didática com cinco dimensões do documento (canção): dimensão material (suporte em que se encontra a narrativa histórica com a qual se pretende trabalhar, bem como o tipo de linguagem), descritiva (o tema e o objeto), explicativa (abordagem do tema em uma narrativa), dialógica (referências de pesquisa e culturais com as quais o texto dialoga e a partir dos quais foi construída a narrativa) e dimensão sensível - sentimentos e afetos que mobilizam a produção e a recepção do texto - (HERMETO, p. 148 e 149).

Em seguida, elabora uma proposta de estudo temático embasada nas canções de Luiz Gonzaga com vistas a discutir, “as representações do nordeste: um regionalismo universal.” Chico Buarque e Ruy Guerra, em o projeto cultural o veto de Calabar, (texto lançado em livro, disco e espetáculo) é abordado na discussão sobre a censura e as diversões públicas durante a Ditadura Militar. Por último, a partir das musicas cérebro eletrônico e parabolicamará, avalia as contribuições de Gilberto Gil, para a temática "trabalho e tecnologias da informação". Didaticamente, foram criadas sequências de ensino, baseadas em um quadro panorâmico que envolve problematização, desenvolvimento da narrativa, aplicação de conhecimentos e reflexão/síntese. Esses passos são mediados por oito atividades que auxiliadas por documentos como letras de músicas, capas de discos, trechos historiográficos e entrevistas oferecem possibilidades de construção de conhecimento.

A meu ver, pelo teor didático e denso da construção do texto, “Canção popular brasileira e Ensino de História”, vai muito além das fronteiras do ensino Médio. Deve ser leitura obrigatória para quem concebe a relação entre saber histórico e saber histórico escolar em qualquer nível do conhecimento, mesmo que não trabalhe em especifico com essa documentação. 